\title{
Behaviour Analysis of Reinforced Soil Retaining Wall According to Laboratory Scale Test
}

\author{
Young Je Kim ${ }^{1}$, Hyuk Sang Jung ${ }^{1, *}$, Yong Joo Lee ${ }^{2}$, Dong Wook $\mathrm{Oh}^{2}{ }^{2}$, Min Son ${ }^{1}{ }^{1}$ and \\ Hwan Hee Yoon ${ }^{1}$ \\ 1 Department of Railroad Construction \& Safety Engineering, Dongyang University, 145 Dongyangdaero \\ Punggi-eup, Yeongju-si 36040, Korea; dudwp0113@naver.com (Y.J.K.); micaell012@naver.com (M.S.); \\ yhh0554@naver.com (H.H.Y.) \\ 2 Department of Civil Engineering, Seoul National Universtiy, 232 Gounneung-ro Nowon-gu, \\ Seoul 01811, Korea; ucesyj1@seoultech.ac.kr (Y.J.L.); loeoh9196@gmail.com (D.W.O.) \\ * Correspondence: yoricom@dyu.ac.kr; Tel.: +82-54-630-1726
}

Received: 24 July 2019; Accepted: 30 November 2019; Published: 30 January 2020

\begin{abstract}
Reinforced soil retaining wall are ground structures that can be readily seen all around us. The development of reinforcements to these walls and their demand have increased rapidly. These walls are advantageous because they can be used not only in simple construction compared with reinforced concrete retaining walls but also when the height of the wall needs to be higher. However, unlike reinforced concrete retaining walls, in which the walls are integrated and resist the earth pressure on the back, the block-type reinforced earth retaining wall method secures its structural stability by frictional force between the buried land and reinforcements. A phenomenon in which a block is cracked or dropped owing to deformation has been frequently reported. In particular, this phenomenon is concentrated at the curved parts of a reinforced soil retaining wall and is mainly known as a stress concentration. However, to date, the design of reinforced soil retaining walls has been limited by the two-dimensional plane strain condition and has not considered the characteristics of the curved part. There is a lack of research on curved part. Therefore, this research determines the behavioural characteristics of curved-part reinforced soil retaining walls with regard to the shape (convex or concave) and angle $\left(60^{\circ}, 90^{\circ}, 120^{\circ}\right.$, and $\left.150^{\circ}\right)$. The displacement generated in the straight part and the curved part was analysed through an Laboratory Scale Test. The results showed that the horizontal displacement of the curved part increases as a convex angle becomes smaller, and the horizontal displacement of the curved part decreases as a concave angle becomes smaller. At the center ( $\mathrm{D}$ and $\mathrm{H}$ have the same length, but $\mathrm{H}$ represents the height and $\mathrm{D}$ represents the separation distance from the center of the curved part) of the convex curve, the horizontal displacement of the $0.5 \mathrm{D}$ section decreased to $13.8 \%$; it decreased to $41.0 \%$ in the $1.0 \mathrm{D}$ section. For concave angles, it was revealed that the horizontal displacement from the center $0.0 \mathrm{D}$ to the $0.5 \mathrm{D}$ section of the curved part increased by $25 \%$, and from the $1.0 \mathrm{D}$ section, by $75 \%$. It was confirmed that the displacement difference was largely based on the value of $0.5 \mathrm{D}$. It was judged that this can be used as basic data for the design and construction guidelines for reinforced soil retaining wall of reinforced soil retaining walls.
\end{abstract}

Keywords: reinforced soil retaining wall; curved-part; horizontal displacement; laboratory scale test

\section{Introduction}

The reinforced soil retaining wall (RSW) method was first introduced by Herri Vidal (1963) and has since become one of the civil engineering structures that can be seen all around us. Then, reinforcements were developed for this type of wall. The RSW method secures structural stability 
through the frictional force between the embankment and the reinforcement by installing reinforcements and walls simultaneously with the embankment. In Korea, these walls were first constructed in 1980. This type of wall is easier to construct than reinforced concrete retaining walls, can be applied to high-filling land, and is widely used. Therefore, many researchers and engineers have studied the RSW method.

In addition, research on the performance of substantially improved reinforcements, simpler construction methods is underway [1]. Research on the stability of this type of wall has been limited to the stability of the straight part assumed under a two-dimensional strain [2]. However, this does not fully reflect the characteristics of actual installed RSWs, as many cracks and dropouts have been reported in the wall block owing to excessive displacement occurring at the curvilinear portion [3]. Therefore, it is necessary to study the displacement generated at the curved part of the RSW.

At present, the design of the RSWs in Korea is mainly created by a two-dimensional numerical analysis under two-dimensional plane strain conditions. However, the design of the RSWs through this two-dimensional numerical analysis is limited by its inability to reflect the behavior of the curved part of the RSWs constructed at the field site. These have a limit that the behaviour of the curved part of RSWs constructed in the field cannot be reflected [4]. Therefore, in this study, the curved part of a RSW was reproduced through a laboratory test, and the displacement of the straight part and the curved part were analysed. The angle of the curved section was varied at $60^{\circ}, 90^{\circ}, 120^{\circ}$, and $150^{\circ}$, and the shape was changed between convex and concave in order to analyse the displacement of the straight part and the curved part with regard to the angle and shape.

The displacement of an entire RSW face were analysed using a close range photogrammetry during the laboratory model test. The displacement generated at each position of the wall according to the shape and angle as well as position of maximum displacement and its change are analysed in this study.

\section{Literature Review}

\subsection{Case Study}

Figure 1 shows cases of curved part collapse of RSWs for each type of shape. Figure 1a represents a crack in the concrete block, which occurred in a curved part of a $15 \mathrm{~m}$ high single RSW with the main cause being the strain concentration arising from the insufficient length of reinforcements. Figure $1 \mathrm{~b}$ shows excessive bulging in the curved part. Figure $1 \mathrm{c}$ shows a collapse site caused by foundation subsidence, drainage failure, heavy rainfall, etc., and the entire curved part, $20 \mathrm{~m}$ in height and $80 \mathrm{~m}$ in length, has collapsed. Finally, Figure $1 \mathrm{~d}$ shows that the site collapsed due to poor compaction of the back fill and a lack of bearing capacity of the fill-up ground foundation. The collapse occurred in a curved part $10 \mathrm{~m}$ in height and $40 \mathrm{~m}$ in length. The cause of the failure was poor compaction and a lack of bearing capacity of the foundation. The problems in design and construction were analysed. There is a high possibility that a collapse will lead to secondary and tertiary accidents. As can be seen above, a secondary accident may occur if there are structures around RSWs, and extra caution is required for safety [5].

\subsection{Design Code}

When designing and constructing RSWs in Korea, the criteria for examination and construction to ensure the stability of the curved section are unclear. The structural foundation design standard of the Korean Geotechnical Society [6] mentions the failure conditions of the curved part of a RSW and the load condition acting on the reinforcing material.

\subsubsection{Domestic}

Standard, The standard specification code (KDS 118010: [7]), which is a standard to be followed at the time of construction, requires the approval of the owner or supervisor regarding the radius 
and the method of embankment construction for the curved part. The current situation is that design and construction standards are not clearly presented for the curved part of the RSWs, and, under this condition, internal and external stability are being examined through limit equilibrium analysis. Figure 2 shows the design criteria of the curved part of a RSW.

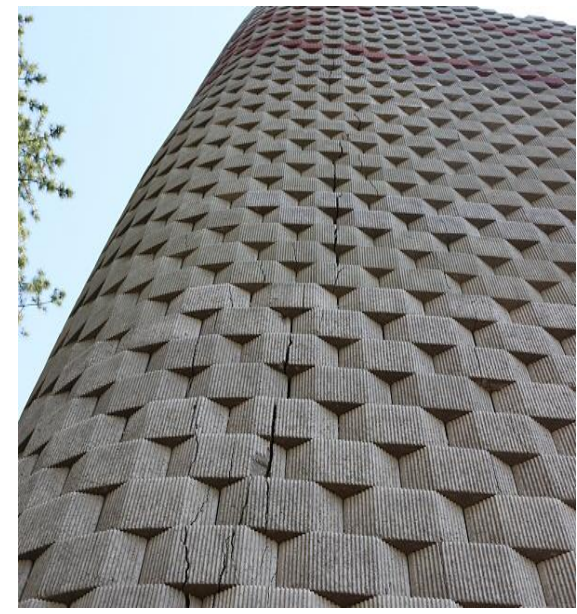

(a)

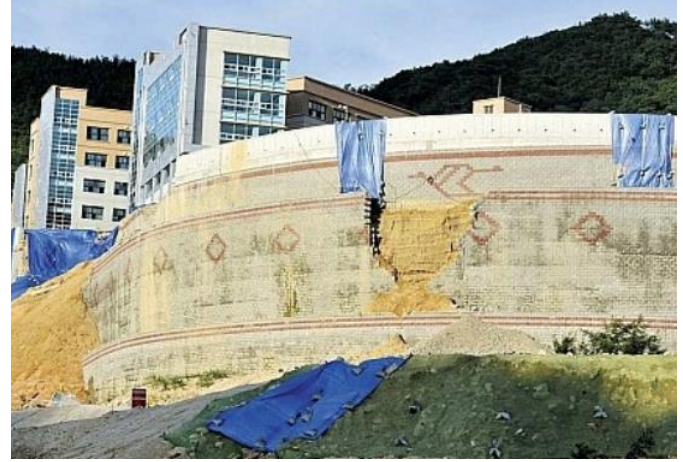

(c)

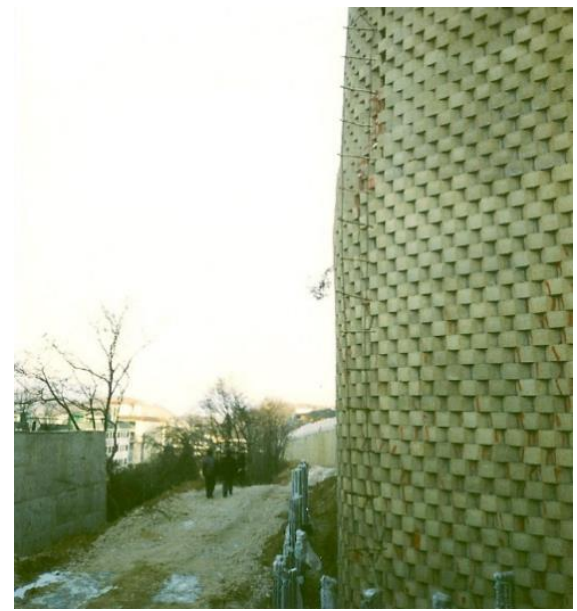

(b)

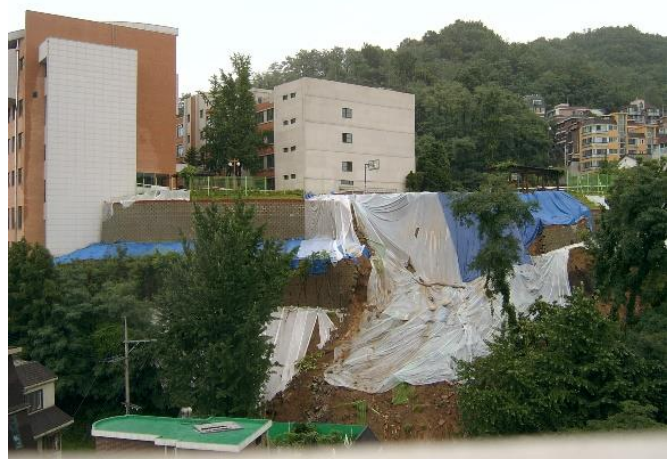

(d)

Figure 1. Collapse of reinforced soil retaining wall: (a) Crack (Andong in Korea); (b) Bulging (Icheon in Korea); (c) Collapse-I (Ulsan in Korea); (d) Collapse-II (Seoul in Korea).

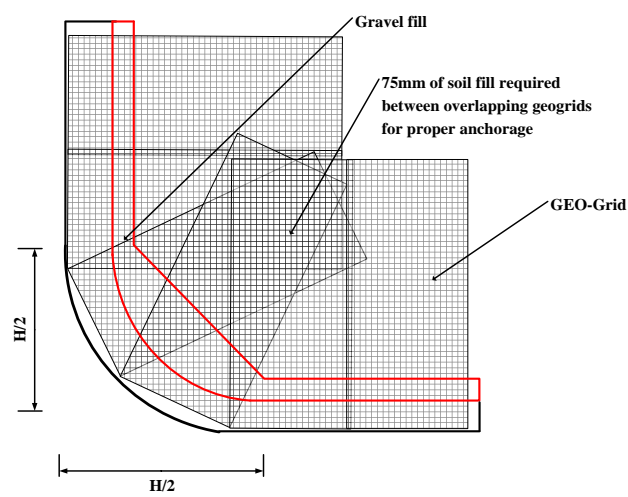

(a)

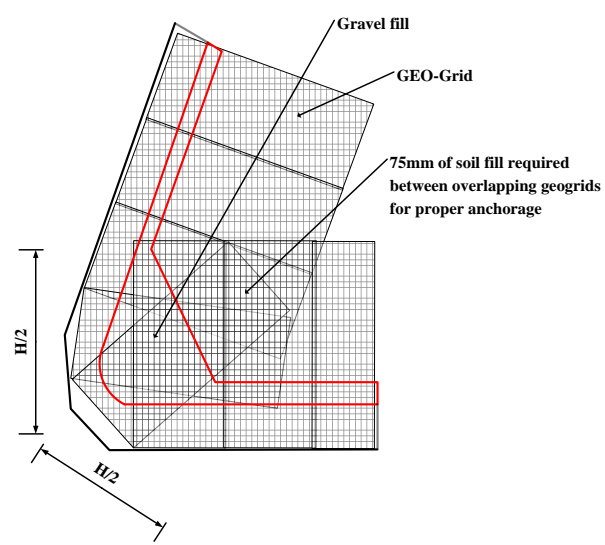

(b)

Figure 2. Cont. 


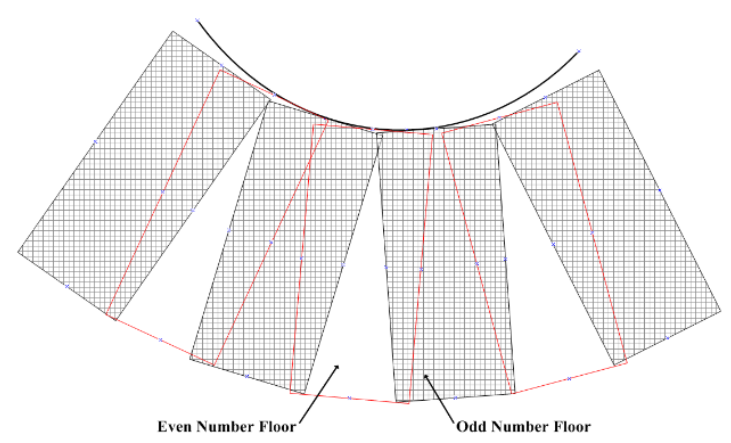

(c)

Figure 2. Installed stiffener at curve section of mechanically stabilized earth wall: (a) In case of convex section; (b) In case of acute angle; (c) In case of concave section.

\subsubsection{Overseas Standard}

The Federal Highway Administration (FHWA, 2009) [8], the National Highway Administration (AASHTO, 2012) [9] and the North American Association of Concrete Stones (NCMA, 2016) [10] are referred as representative geosynthetics reinforced soil wall design method applied to the oversea construction.

According to FHWA (2009), it is mentioned regarding an acute part of RSW that "wall angle points with an interior angle of less than 150 degrees shall be considered to be a wall corner. the wall corner shall provide a positive connection between the sections of the wall on each side of the corner such that the wall backfill material cannot spill out through the corner at any time during the design life of the wall."

In the AASHTO (2012), it is noted with respect to definition of curved part of the RSW that "The curved part is defined as the intersection of the two walls at or below 120 degrees." and is applied need and to domestic design manual.

NCMA (2016) has state regarding how to set reinforced material at the curved part that "When the gaps between adjacent geogrid exceed 20 degrees, place additional reinforcement on next course of segmental units immediately above the specified placement elevation, in a manner that eliminates gaps left by previous layer of geosynthetic. Repeat for subsequent courses where geogrid is specified to be located."

\subsection{Literature Review}

Currently, models of RSWs are being continuously studied through model experiments, numerical analysis methods, and in-situ measurements.

Wong et al. [11] built a RSW using a reinforcement with a tensile strength of $47 \mathrm{kN} / \mathrm{m}$ in of size $1.0 \mathrm{~m} \times 2.0 \mathrm{~m} \times 1.2 \mathrm{~m}$ (length $\times$ width $\times$ height). A model test was conducted to analyze influence of the overburden load on behavior of the RSW. The failure phenomenon was analyzed by varying the installation interval and length of reinforcements and applying the built load of the RSWs. The actual RSW and the block, were used for model test without similarity law, so there was a limit in comparing to field condition of RSW. Installation interval of reinforcement, length, and the analyse of the back on the behavior and fracture mechanisms of the RSW.

$\mathrm{Ki}$ et al. [12] conducted a labrotory scale tset in which Linear Variable Differential Transducers (LVDT) were installed at intervals of $15^{\circ}$ from a wall, and the similarity law was applied to analyse the behaviour related to the form of the curved part of the RSW (Figure 3). The reinforcement used in the experiment was paper with a tensile force of $0.034 \mathrm{kN} / \mathrm{m}$, an LVDT was installed $(18,34,50$, and $58 \mathrm{~cm}$ ) on the RSWs of $64 \mathrm{~cm}$ in height, and the difference between the displacement of the curved and straight parts was analyzed. In the case of a convex curve, it was confirmed that a horizontal 
displacement of about 2.82 to 3.52 times that of a concave curve occurred. However, it can be said that the four LVDTs alone were insufficient to determine the behaviour of the front of the RSW.
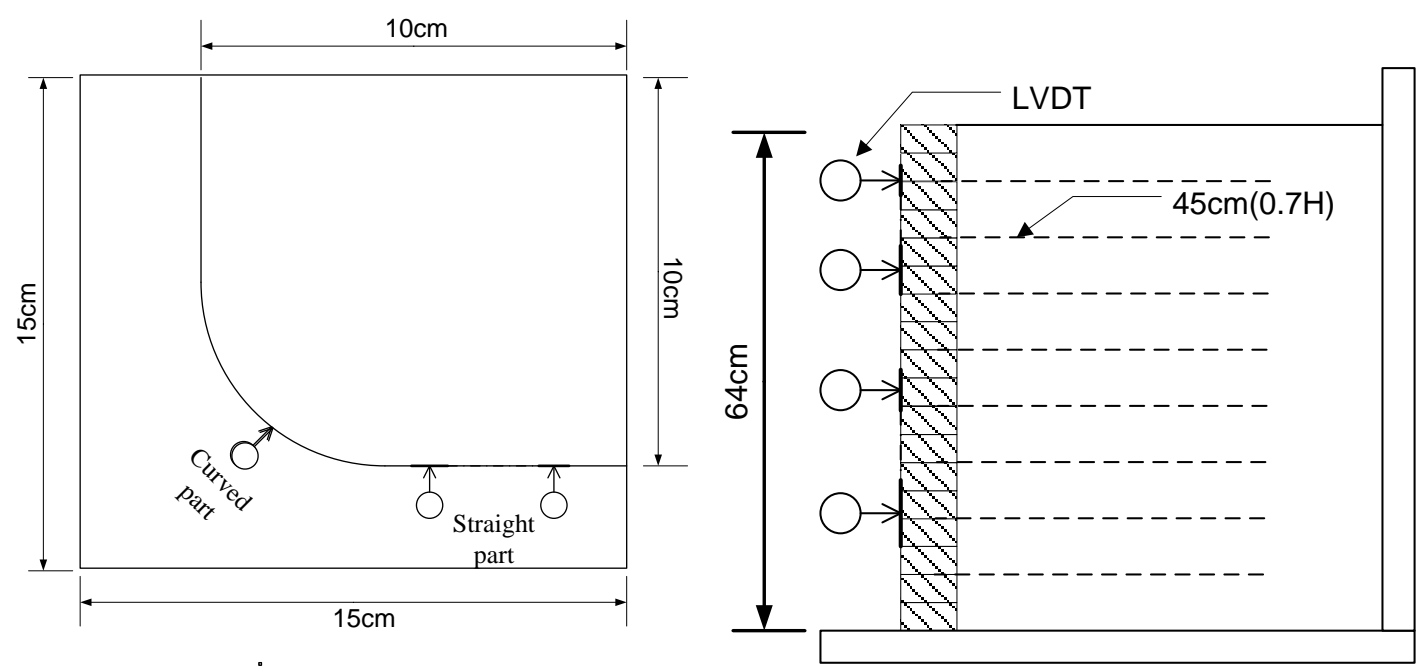

Figure 3. Model experiment overview plot [12].

Lee et al. [13] measured the bulging of the wall in a model soil tank (Figure 4), compared the behaviour of curved and straight part varying the shape of a RSW, the overburden load, and the installation offset of the reinforcement material. It was confirmed that the maximum horizontal displacement of the RSW increased as the tensile strength of the reinforced material increased. However, similarity law was not applied, and there was a limit to reproduce the actual RSW. There were also difficulties in copying the blocks on a wooden board and judging the block-by-block behaviour.

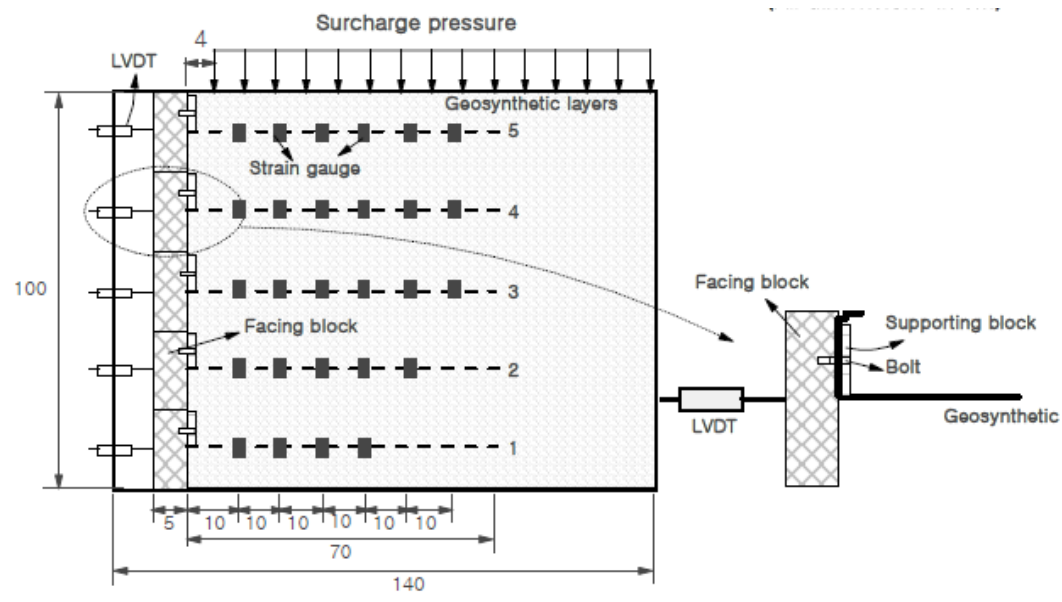

Figure 4. Cross-section of the model wall [13].

Lee et al. [14] compared the behaviour of curved and straight part varying the shape of a RSW through three-dimensional numerical analysis considering the internal friction angle and relative density (Figure 5). However, the effect of the uncertainty error at the time of actual construction could not be determined, and the analysis of the occurrence of substantial horizontal displacement was insufficient. 


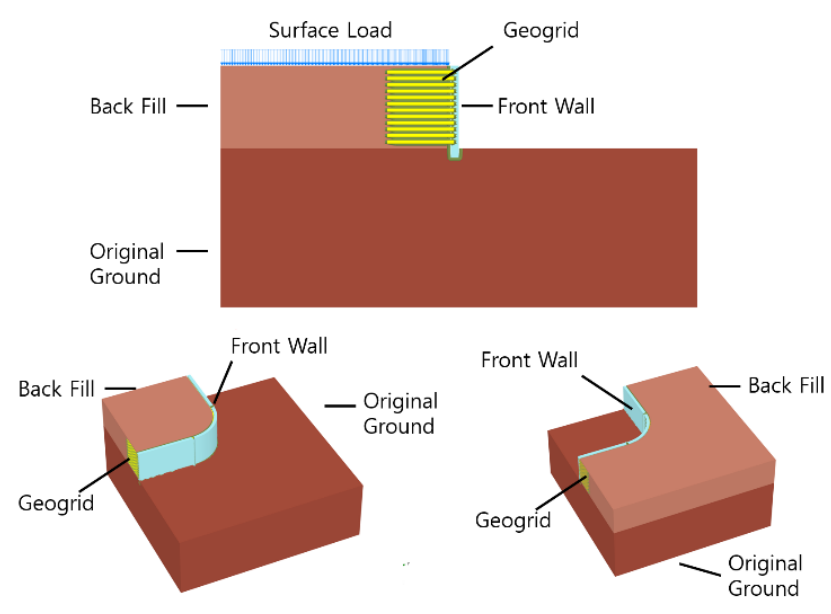

Figure 5. Modeling of numerical analysis [14].

\section{Laboratory Scale Test}

\subsection{Equipment}

In order to analyse the displacement of the straight and curved parts of a RSW, an laboratory scale test was carried out, and a model soil tank was produced for this purpose. The model was produced with dimensions of $2 \mathrm{~m} \times 2 \mathrm{~m} \times 1 \mathrm{~m}$ (length $\times$ width $\times$ height) (Figure 6). The model was designed to be able to install a model RSW by applying a $1 / 6$ similarity ratio of a RSW with a circular height of $4.4 \mathrm{~m}$ and a width of $12 \mathrm{~m}$.

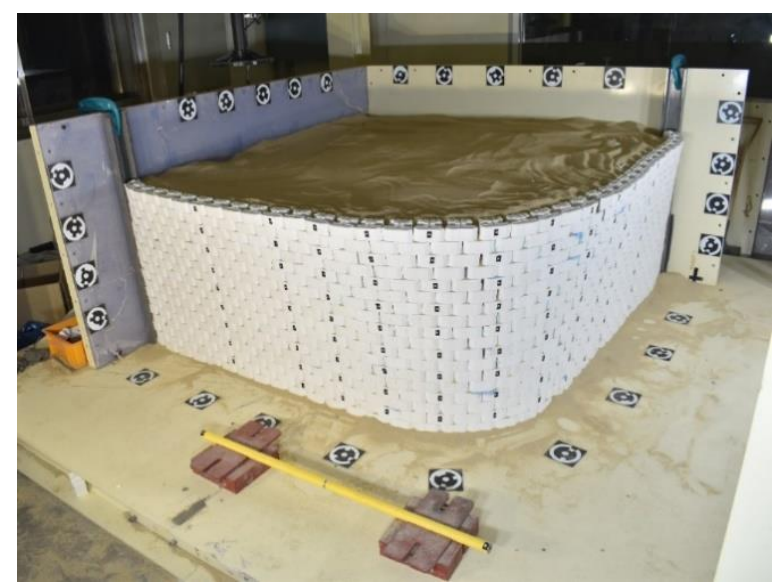

(a)

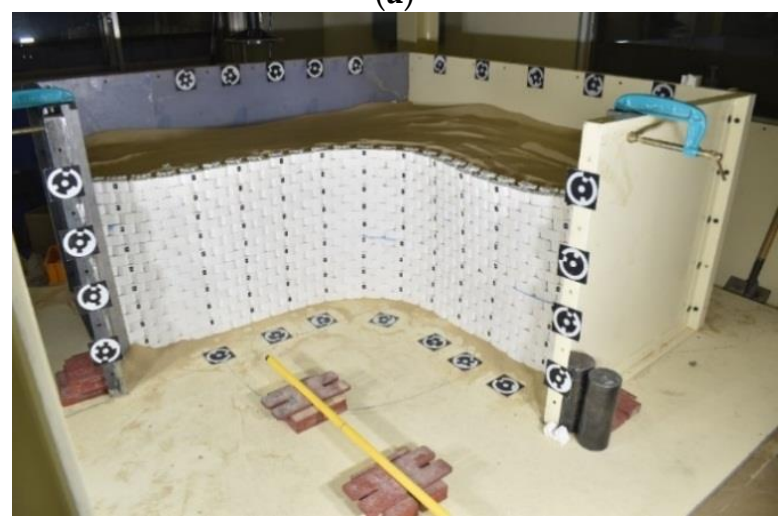

(b)

Figure 6. Soil tank for laboratory scale test: (a) Convex 90; (b) Concave 90. 
Geosynthetics were calculated to replicate the circular RSW in a tensile strength test. The tensile strength of geosynthetics was also applied by the similarity law, as the $1 / 6$ ratio was applied to the tensile strength test. Therefore, the tensile strength of each material that could be used as a geosynthetics was measured and compared with the tensile strength of a geosynthetics used in an actual RSW (Table 1).

Table 1. Tensile strength of a reinforcing material.

\begin{tabular}{cccccccc}
\hline & \multicolumn{2}{c}{ Calculated } & \multicolumn{4}{c}{ Lab. Test Results } \\
\hline & Prototype & Model & No. 1 & No. 2 & No. 3 & No. 4 & No. 5 \\
\hline Tensile strength (kN/m) & 50 & 0.23 & 18.38 & 8.42 & 6.17 & 7.17 & 3.4 \\
Tensile elongation $(\%)$ & 8 & 8 & 32.2 & 1.7 & 16.3 & 70 & 39.6 \\
\hline
\end{tabular}

According to Yoo et al. [15], the tensile strength of the general reinforcement used in the RSW was $50 \mathrm{kN} / \mathrm{m}$, and applying similarity law, it should be a material with a tensile strength of $0.23 \mathrm{kN} / \mathrm{m}$. As a result of measuring the tensile strength of each material, A shown in Table 1, as a result of experimenting with reinforcements one through five in previous studies, we learned that when reinforcements with high tensile strength and low tensile elongation were used, the displacement difference between the straight and curved parts was about 1-2 mm. Based on these results, it was thought that it would be difficult to analyze the displacement patterns. Therefore, reinforcement No. 5 was selected for this study. Figure 7 shows the geosynthetics used in the laboratory scale test.

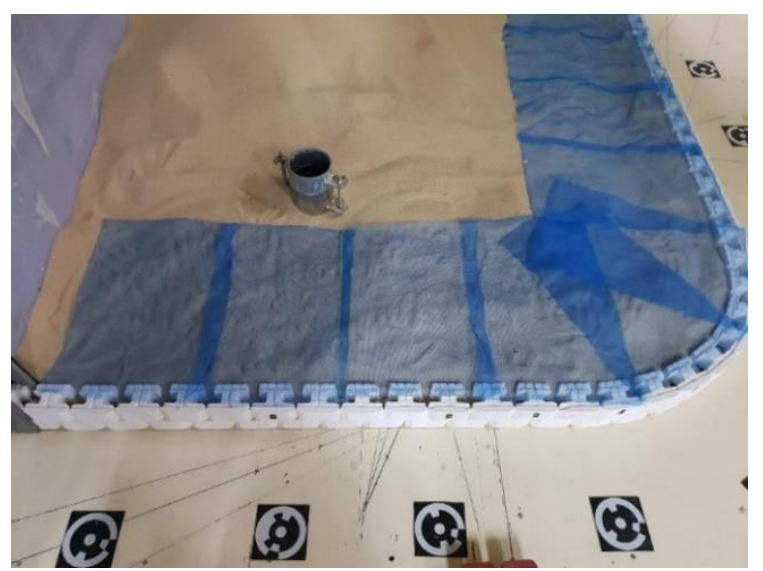

Figure 7. Reinforce used in the indoor model experiment.

A block was made to replicate the wall of the RSW. Figure 8 shows the sizes of the blocks used in general block-type RSW construction and the blocks used in the laboratory scale test. The similarity ratio was also applied to the size of the block of the model, and the fastening with the geosynthetics was facilitated through the unevenness on the upper and lower portions of the block.
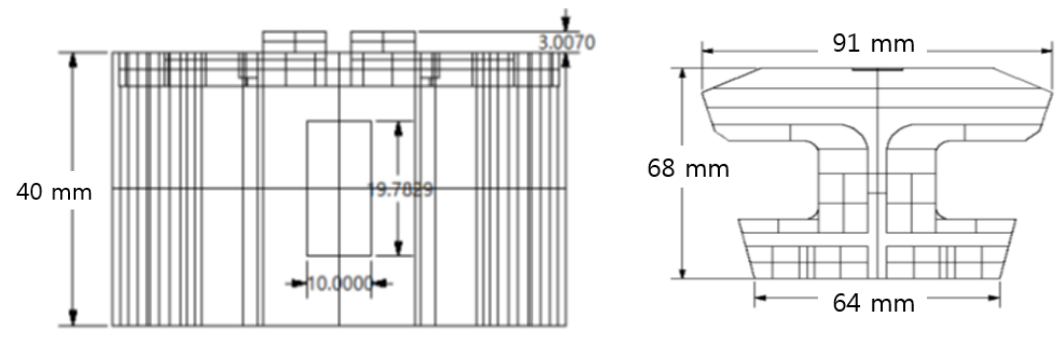

Figure 8. Dimension of wall block model.

RSW's backfill was formed using the sand pouring device (Figure 9). In the laboratory scale test, the soil used as backfill was standard sand, which was classified as SP in the Unified Soil Classification 
System, and its specific gravity was 2.6. The internal friction angle was $41.3^{\circ}$ based on a direct shear test that used the same relative density as the indoor model experiment to determine the strength parameters of the standard sand. The relative density of the backfill could be adjusted through the height of the device. In this study, the relative density of the backfill was closely examined. By using the research of Jung [16], the height of the pouring was maintained at $800 \mathrm{~mm}$ from the ground, and the relative density was $70 \%$ so that the determination of the formed ground was made at $90 \%$ or higher. $70 \%$ of the relative density at a sand pouring height of $800 \mathrm{~mm}$ was confirmed through a preliminary sand pouring experiment.

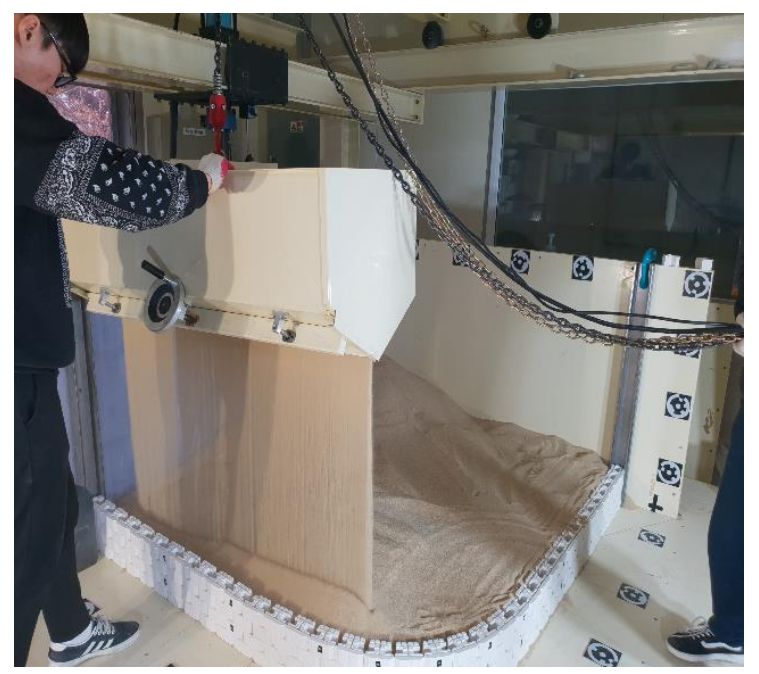

Figure 9. Sand pouring.

\subsection{Method}

A sand puring device to keep the relative density $\left(\mathrm{D}_{\mathrm{r}}\right)$ constant at about $70 \%$ by performing preliminary experiments when building RSWs in model tests. The height was maintained at $800 \mathrm{~mm}$ to ensure aim of relative density, it was confirmed about $90 \%$ or over. Figures 10 and 11 shows sequence diagram of experiment and laboratory model.

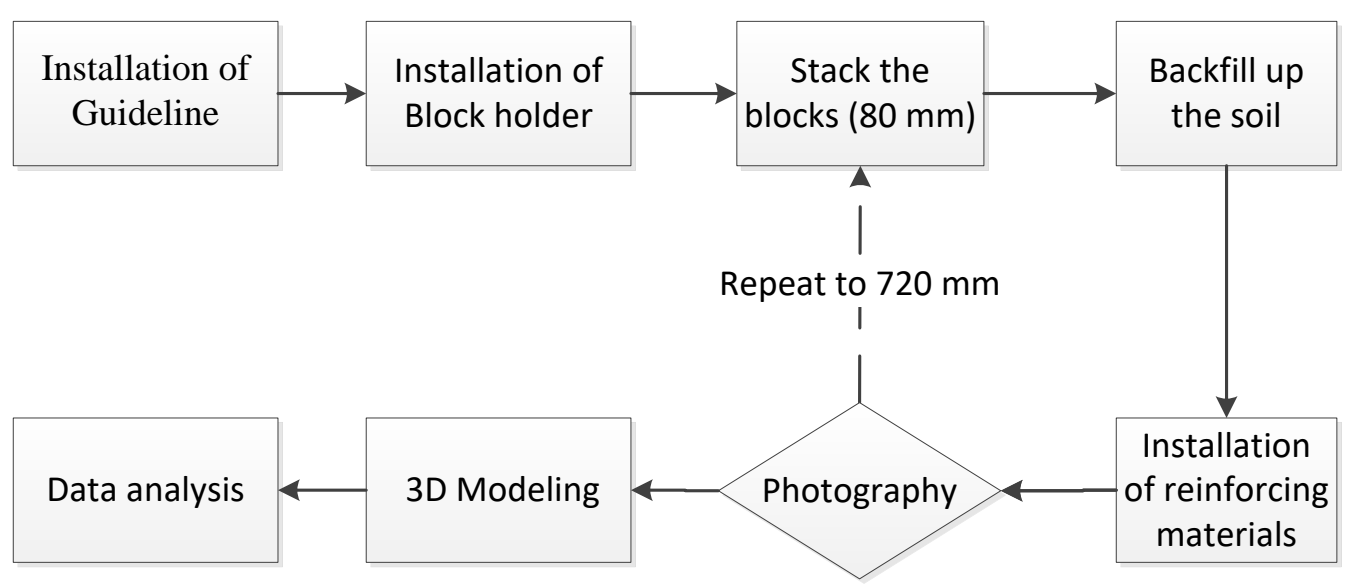

Figure 10. Sequence diagram of experiment.

In order to consider the behavioural according to the form and angle of the wall, it was divided into concave(CCV) and convex(CVX) forms according to shape, as shown in Table 2, and the angles were $60^{\circ}, 90^{\circ}, 120^{\circ}$, and $150^{\circ}$. Eight cases of model test were conducted (Figure 12). 


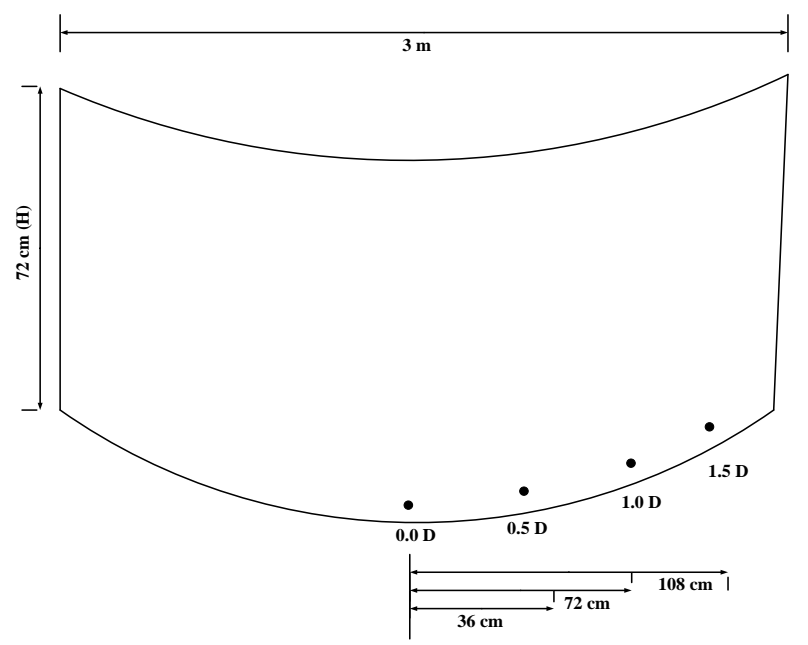

(a)

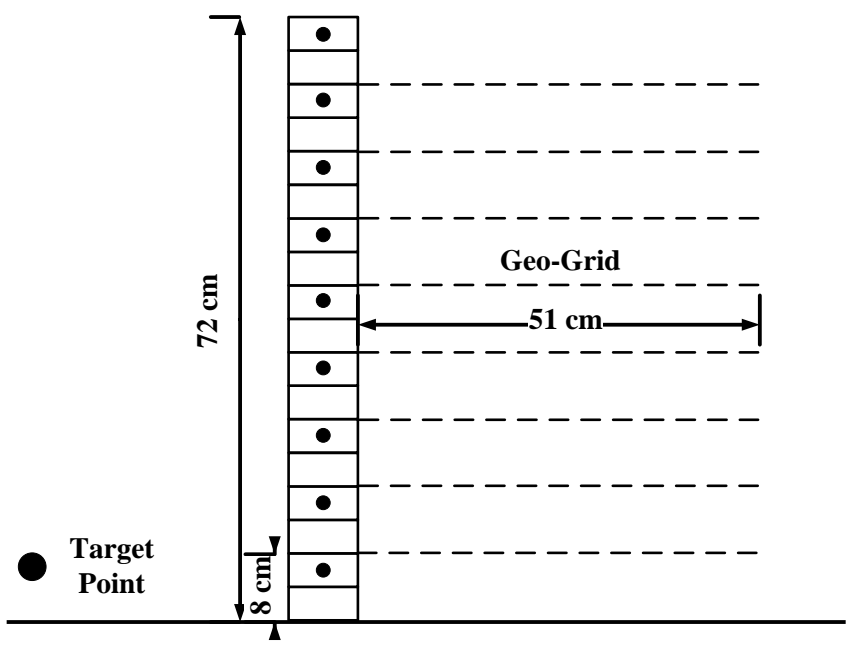

(b)

Figure 11. Laboratory model: (a) A plane view; (b) A side view.

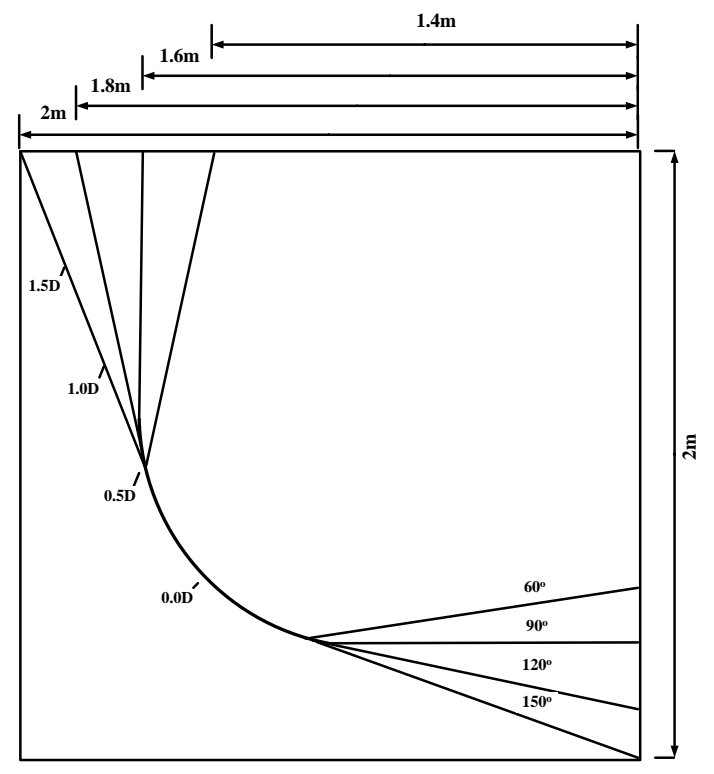

Figure 12. Angle of the RSW model. 
Table 2. Tested cases.

\begin{tabular}{ccccc}
\hline \multirow{2}{*}{ Type of the Shape } & \multicolumn{4}{c}{ Type of Angle } \\
\cline { 2 - 5 } & $\mathbf{6 0}^{\circ}$ & $\mathbf{9 0}^{\circ}$ & $\mathbf{1 2 0}^{\circ}$ & $\mathbf{1 5 0}^{\circ}$ \\
\hline Convex & CVX 60 & CVX 90 & CVX 120 & CVX 150 \\
Concave & CCV 60 & CCV 90 & CCV 120 & CCV 150 \\
\hline
\end{tabular}

\subsection{Measument Method of Analysis}

The Photo Modeler Scanner (PMS [17]) is a software that creates 3D shape information based on a picture of the target object, and uses pictures taken from various angles to display different positions [18]. This information was used to calculate the intersection of light from each photo location and convert it to a 3D model.

PMS not only generates 3D models without contact using only two or more photos, but also has vertices that can be measured three-dimensionally with high accuracy within an error range of 0 to $9 \mathrm{~mm}$ in a range of 3 to $5 \mathrm{~m}$, so it has a further advantage in measuring the displacement generated during construction than the method using laser scanning. Figure 13 shows a conceptual diagram of PMS.

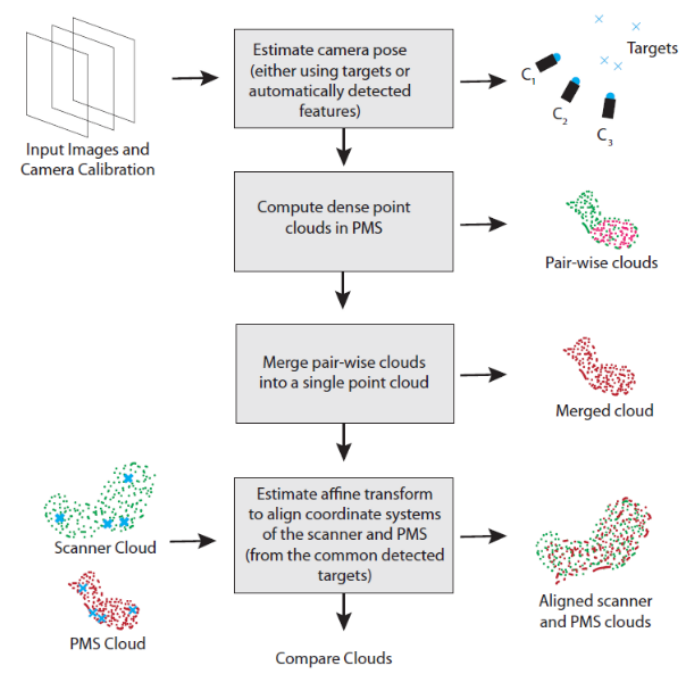

Figure 13. Drawing of conceptual PMS [17].

\section{Results}

\subsection{Analysis of the Planar Area}

Figure 14 shows the results of PMS for each case. Figure 14a shows the displacement generated in all sections of the convex RSW and was divided according to the angle. The y-axis indicates the height of the model RSW, and x-axis length from the center of corner $(0.0 \mathrm{D})$ to the end of straight part $(1.5 \mathrm{D})$. Here, $\mathrm{D}$ is the same as the height of the RSW H, and is denoted by D to distinguish it from the height of the RSW. For the convex type, it was shown that the maximum displacement occurred at the center of the curve, that is, at the $0.0 \mathrm{D}$ point regardless of the angle. In addition, the displacement decreased $(1.5 \mathrm{D} /-1.5 \mathrm{D})$ as the separation distance increased. In addition, it was found that the maximum displacement generated at the $0.0 \mathrm{D}$ point increased as the angle of the curved part decreased

The case of concave shape shown in Figure 14b, it was opposite to the convex displacement trend. From the $0.0 \mathrm{D}$ point, it is clear that the displacement was smaller than that for the straight part, and it was found that the minimum displacement occurred. A quantitative analysis of the resulting value of the displacement generated in this test, which was judged to be owing to the arching effect, The arching effect refers to a phenomenon in which the vertical shear force caused by the settlement of the backfill 
decreases the working load in the vertical direction and consequently reduces the horizontal strain [19]. The result of this test shows that the concave-shaped type has a relatively small displacement in the curved part than in the straight part. This phenomenon is attributed to the deformation suppression of curved parts due to the arching effect.

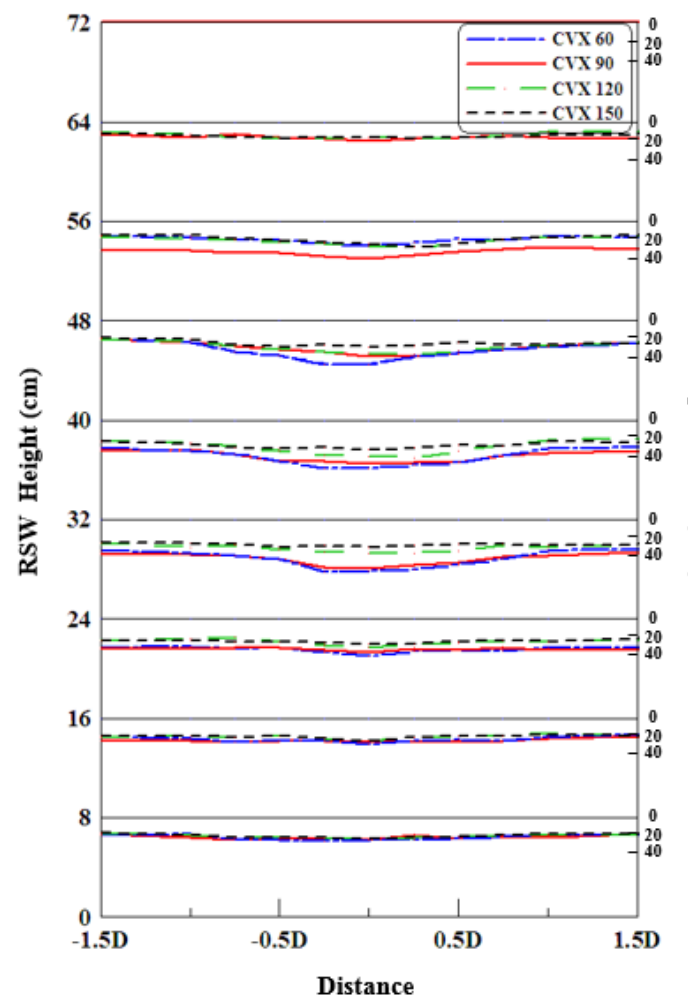

(a)

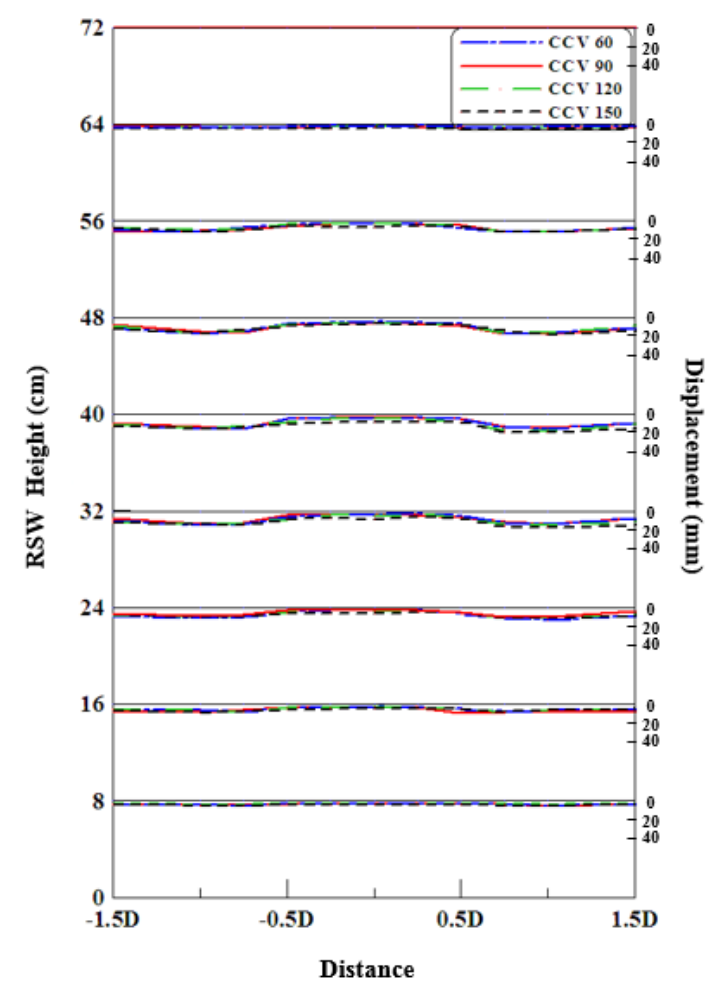

(b)

Figure 14. Result of horizontal displacement for convex and concave type: (a) Convex; (b) Concave.

\subsection{Analysis of the Height}

In convex cases, the displacement generated at each point is shown in Figure 15 according to the angle. The displacement generated at the center of the curved part $(0.0 \mathrm{D})$ was analysed according to the angle in Figure 15a. When the angle of the curved part was $60^{\circ}$ (CVX 60), the maximum displacement generated was largest, at $41 \mathrm{~mm}$. In the case of CVX 90, the maximum displacement appeared at $39 \mathrm{~mm}$ and was shown at $29 \mathrm{~mm}$ and $24 \mathrm{~mm}$ for CVX 120 and 150, respectively. The maximum displacement occurred at CVX 60 and 90 where the height of the RSW appeared at about $380 \mathrm{~mm}$ on the base, that is, $0.53 \mathrm{H}$. For CVX 120 and 150, the maximum displacement occurred at $0.4 \mathrm{H}$. Figure $15 \mathrm{~b}$ shows the displacement generated at a point separated by $0.5 \mathrm{D}$ from the center of the curve. As can be seen from the Figure, in the case of CVX 60, it was found that a maximum displacement of $36 \mathrm{~m}$ occurred, and maximum displacements of $33 \mathrm{~mm}, 25 \mathrm{~mm}$, and $23 \mathrm{~mm}$ occurred for CVX 90,120, and 150, respectively. The maximum displacement was found to occur at 0.4 to $0.5 \mathrm{H}$ in all cases, which was different from the tendency of $0.0 \mathrm{D}$ at the center of the curve. Figure 15c shows the maximum displacement of each case at a point 1.0 D away from the center of the curve. As shown in Figure 15c, 27 mm, 28 mm, 22 mm, and 19 mm were generated at CVX 60, 90, 120, and 150 , respectively. In addition, the point at which the maximum displacement occurred appears from about 0.4 to $0.5 \mathrm{H}$ from the bottom surface of the RSW, which was the same in all cases. However, it was found that the maximum displacement occurred at a point about $0.1 \mathrm{H}$ lower than $0.5 \mathrm{H}$, and the height became lower. Figure $15 \mathrm{~d}$ shows the displacement surface generated in each case at a distance of 1.5 D from the center of the curve. As shown in Figure 15d, it was found that $25 \mathrm{~mm}, 27 \mathrm{~mm}, 20 \mathrm{~mm}$, and $19 \mathrm{~mm}$ were generated at CVX 60,90,120, and 150, respectively. This is the same value as the 
measured maximum displacement at the $1.0 \mathrm{D}$ point. The height at which the maximum displacement occurred at the $1.5 \mathrm{D}$ point was 0.4 to $0.5 \mathrm{H}$, and 0.4 to $0.5 \mathrm{H}$ at the $1.0 \mathrm{D}$ point.

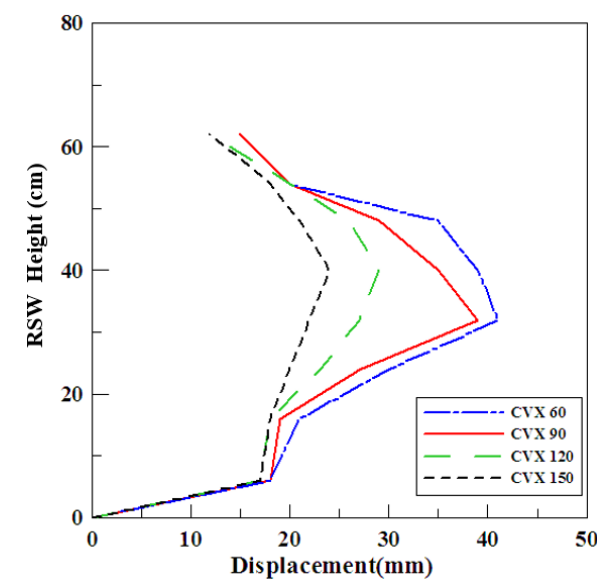

(a)

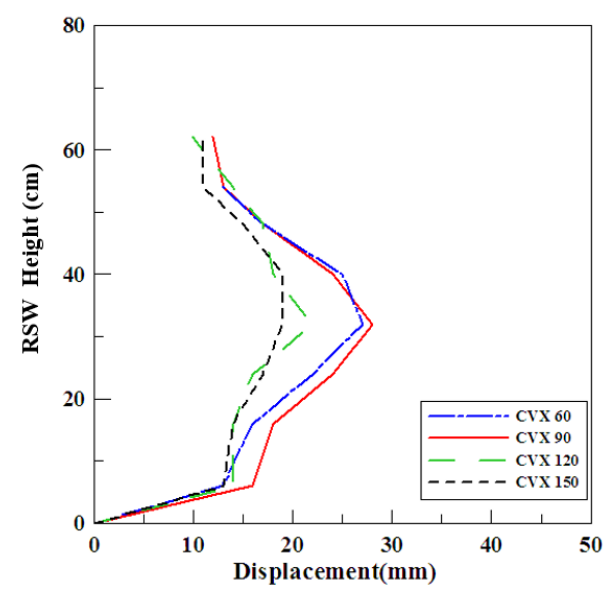

(c)

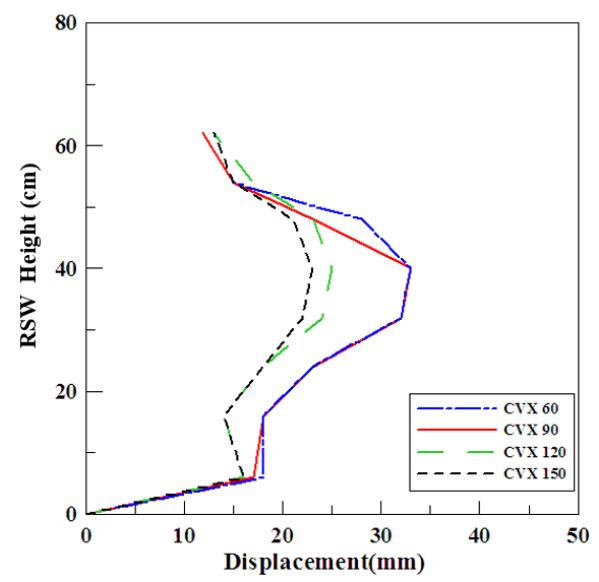

(b)

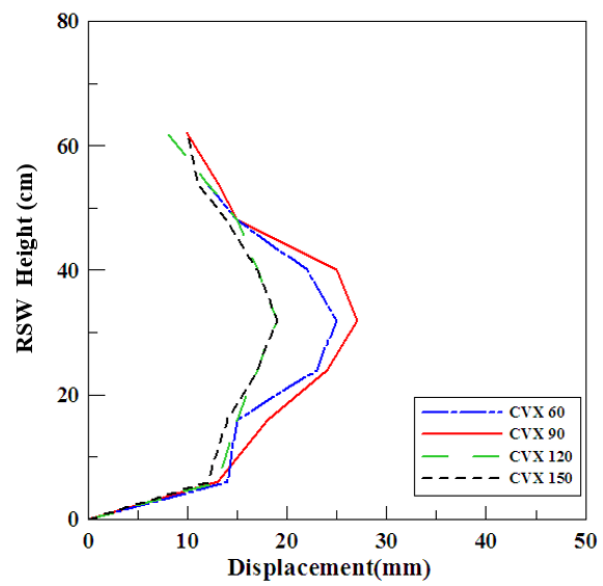

(d)

Figure 15. Horizontal displacement for convex type: (a) 0.0 D; (b) 0.5 D; (c) 1.0 D; (d) 1.5 D.

The displacements according to the heights measured at points $(0.5 \mathrm{D}, 1.0 \mathrm{D}, 1.5 \mathrm{D})$ horizontally separated at the center $(0.0 \mathrm{D})$ of the curved part of the RSW formed in the concave $(\mathrm{CCV})$ form are shown in Figure 16. As shown in Figure 16a, for the concave type, the larger the angle of the curved part, the smaller the maximum displacement. This is opposite to the result obtained with the convex RSW (Figure 15). It was found that the center of the curved part, the maximum displacement generated at the 0.0 D point), appeared at $4 \mathrm{~mm}$ from CCV 60, $4 \mathrm{~mm}$ for CCV 90, $4 \mathrm{~mm}$ for CCV 120, and $7 \mathrm{~mm}$ for CCV 150. It was found that CCV 60 and 90 appeared at $0.5 \mathrm{H}$ construction with respect to than the bottom of the RSW, but CCV 120 and 150 produced the maximum displacement at $0.6 \mathrm{H}$ with respect to than the point where the maximum displacement occurred. The maximum displacements generated at $0.5 \mathrm{D}$ were as follows: CCV 60 to $5 \mathrm{~mm}, \mathrm{CCV} 90$ to $7 \mathrm{~mm}, \mathrm{CCV} 120$ to $7 \mathrm{~mm}$, and CCV 150 to $8 \mathrm{~mm}$. Similar to the results at $0.0 \mathrm{D}, \mathrm{CCV} 60$ and 90 were $0.5 \mathrm{H}$ and CCV 120 and 150 were $0.6 \mathrm{H}$, as was the case with the maximum displacement. The displacement at a point $1.0 \mathrm{D}$ horizontally separated from the center $0.0 \mathrm{D}$ point of the curved part appeared for CCV 60, 90, 120, and 150 at $13 \mathrm{~mm}, 11 \mathrm{~mm}, 14 \mathrm{~mm}$, and $15 \mathrm{~mm}$, respectively, and the $1.5 \mathrm{D}$ points were $9 \mathrm{~mm}, 9 \mathrm{~mm}, 9 \mathrm{~mm}$, and $12 \mathrm{~mm}$, respectively. The height of the point where the maximum displacement occurred at $1.0 \mathrm{D}$ and $1.5 \mathrm{D}$ appeared for $0.6 \mathrm{H}$ at $1.0 \mathrm{D}$ and $0.5-0.6 \mathrm{H}$ for $1.5 \mathrm{D}$, and became similar to the behaviour of the linear part from 1.0 D. As a similar results from convex type, concave maximum displacements 
position is slightly higher as the horizontal distance is further from $0.0 \mathrm{D}$ to $0.5 \mathrm{D}$, and also as angle is larger, which is similar to straight part including CCV 120, 150.

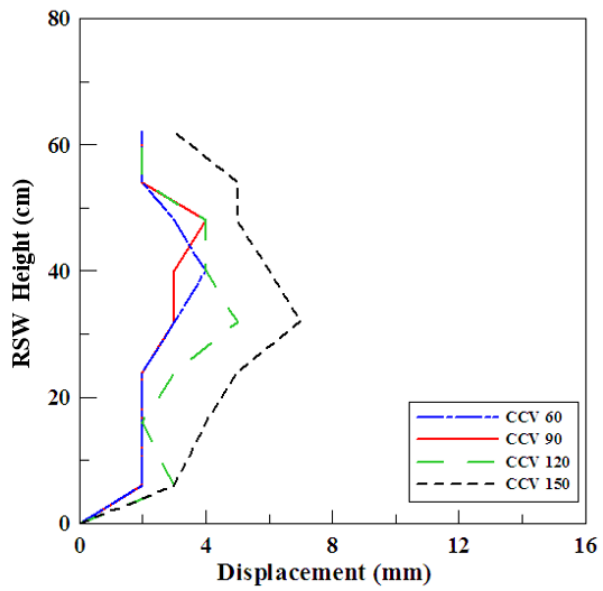

(a)

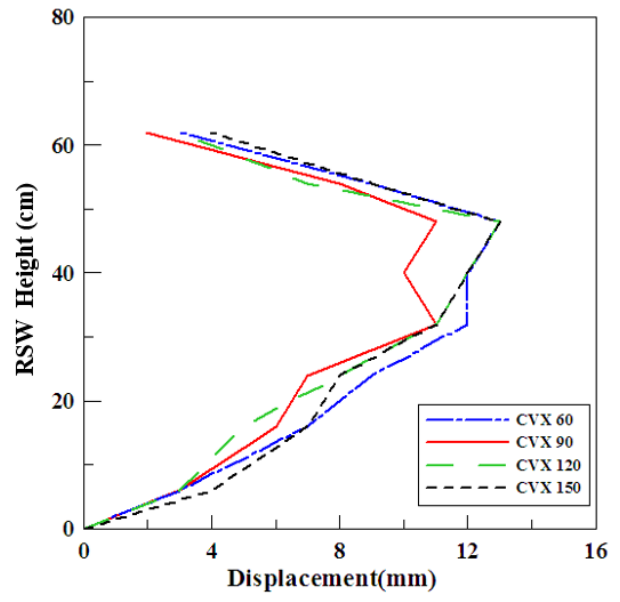

(c)

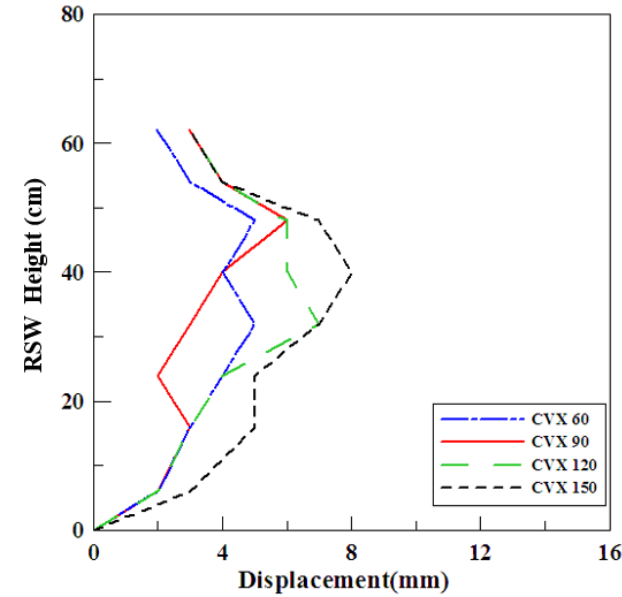

(b)

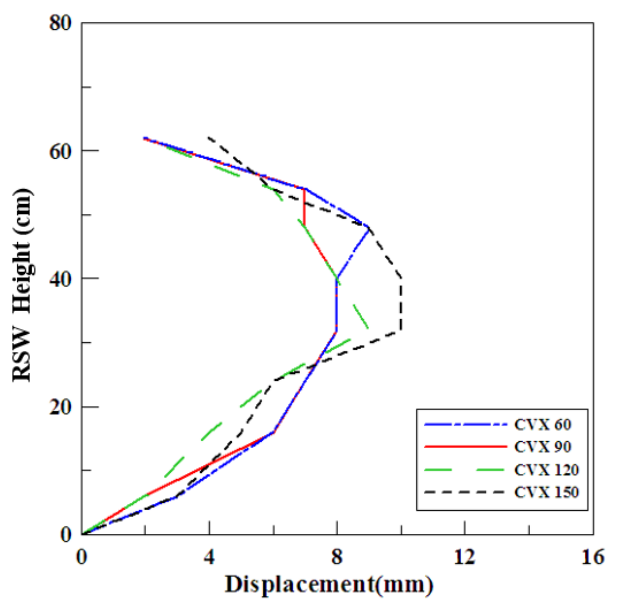

(d)

Figure 16. Horizontal displacement for concave type: (a) $0.0 \mathrm{D}$; (b) $0.5 \mathrm{D}$; (c) $1.0 \mathrm{D}$; (d) $1.5 \mathrm{D}$.

Figure 17 shows the point where the maximum horizontal displacement occurred for each case. As shown in Figure 17a, for the convex type, the maximum horizontal displacement occurrence points are the same as those for CVX 60 and CVX 90, and become the same at $1.0 \mathrm{D}$ and 1.5 D, 0.0 D and 0.5 D. On the other hand, for CVX 120 and CVX 150, the maximum horizontal displacement at 0.0 D occurred at $0.5 \mathrm{H}$, but the maximum horizontal displacement for others $(0.5 \mathrm{D}, 1.0 \mathrm{D}, 1.5 \mathrm{D})$ occurred at $0.4 \mathrm{H}$.

For the concave shape, it was found that the maximum horizontal displacement generation point increased for the convex type, and the reverse $0.0 \mathrm{D}$ was horizontally separated from the center of the $1.5 \mathrm{D}$ curve part (Figure 17b). The points where the maximum horizontal displacement occurred at CVX 60, CVX 90, and CVX 120 appeared at $0.5 \mathrm{H}$ at $0.0 \mathrm{D}$ and $0.5 \mathrm{D}$, and were the same at $0.0 \mathrm{D}$ for CVX 150. However, the height of the maximum horizontal displacement became $0.6 \mathrm{H}$ from CVX 150 to $0.5 \mathrm{D}$. 


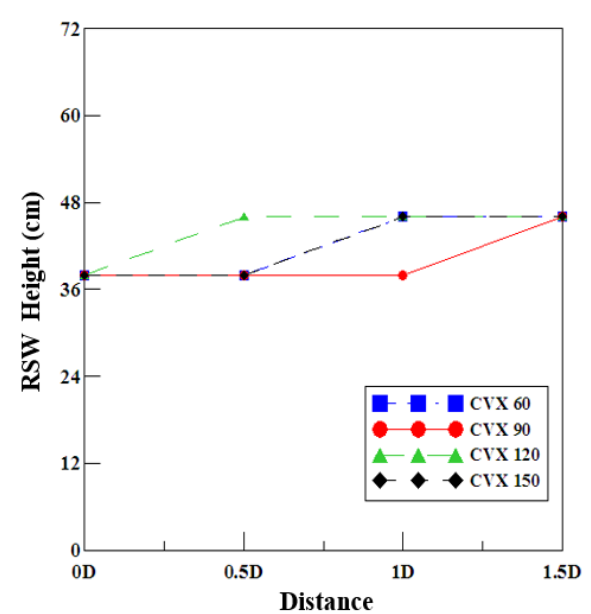

(a)

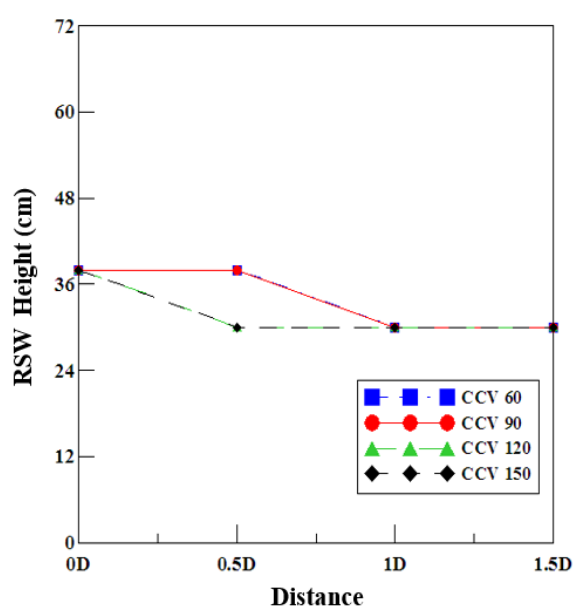

(b)

Figure 17. Height point for max horizontal displacement: (a) Convex section; (b) Concave section.

\subsection{According to Shape}

In comparing the convex (CVX) and concave (CCV) type, the results from convex type of $0.0 \mathrm{D}$ points at the center of the curve and 1.0 D points a which displacement differences occurred are shown according to the angle (Figure 18). In Figure 18a, a value 10.25 times larger than the concave shape appears at the center $0.0 \mathrm{D}$ point of the curved part at $60^{\circ}$, and a value of 2.9 times larger than the convex shape is displayed for the $0.5 \mathrm{D}$ point. It differs from the tendency of the center $(0.0 \mathrm{D})$ of the curve part. For $90^{\circ}$ cases, as shown in Figure 18b, a value that is 10.1 times larger than the concave shape appears at $0.0 \mathrm{D}$, and a value that is 2.35 times larger at $0.5 \mathrm{D}$ appears, for $120^{\circ}$ cases.

As shown in Figure 18c, a value 6.9 times larger appears at 0.0 D, and a value twice that of $0.5 \mathrm{D}$ appears. For $150^{\circ}$ cases are illustrated in Figure $18 \mathrm{~d}$. a value that is four times larger appears at $0.0 \mathrm{D}$ and becomes a value that is 1.63 times larger at $0.5 \mathrm{D}$. In all cases, the convex form appeared to be larger than the concave form, and the difference decreased as the angle increased.

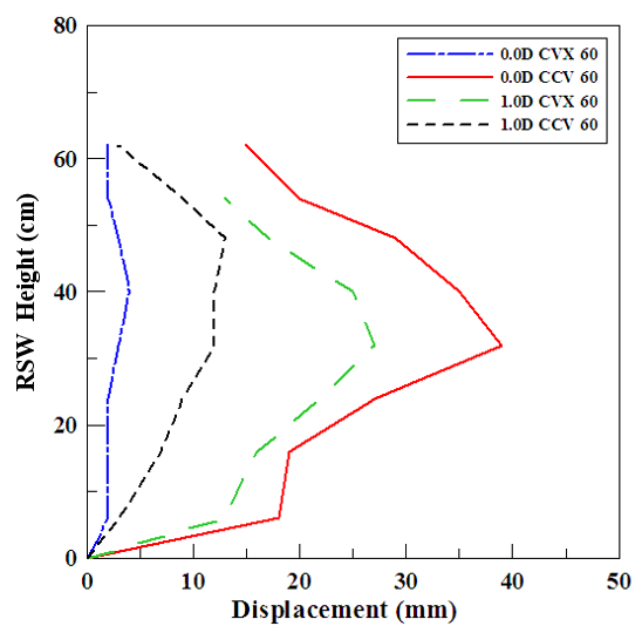

(a)

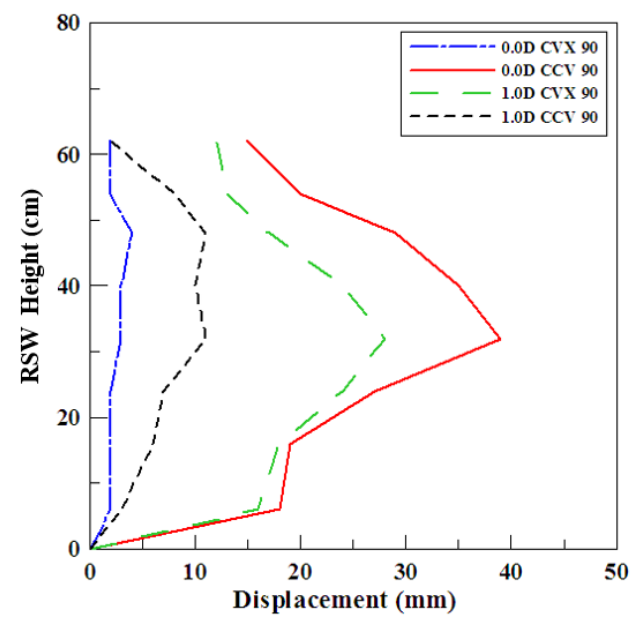

(b)

Figure 18. Cont. 


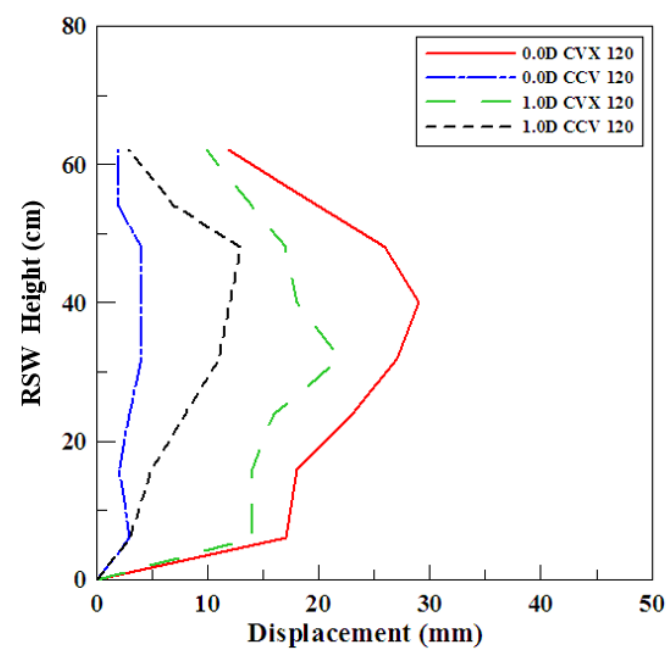

(c)

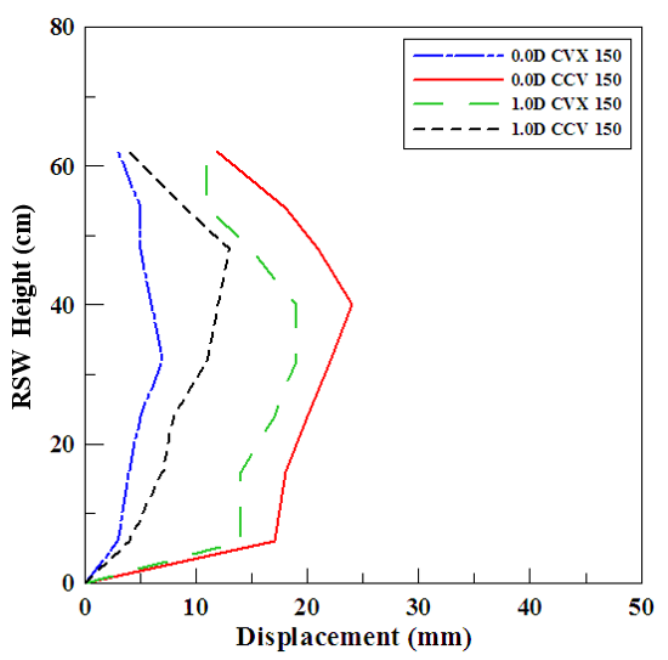

(d)

Figure 18. Horizontal displacement for according to shape: (a) 60 Degree; (b) 90 Degree; (c) 120 Degree; (d) 150 Degree.

\section{Conclusions}

In order to evaluate the influence of the form and angle of a RSW on curved and straight part, an laboratory scale test was conducted, and the experimental results were analysed and summarized as follows.

1. Analysis of the planar region showed that, in the case of convex-shaped walls, the horizontal $\mathrm{CCV}$ displacement of $120^{\circ}$ or less decreases as the separation distance from the center of the curved part $(0.0 \mathrm{D})$ increases and converges to the straight part from the $1.0 \mathrm{D}$ point. Horizontal displacements above a CCV of $120^{\circ}$ were similar from the center of the curved part to the $1.5 \mathrm{D}$ point. Therefore, for the convex wall with a CCV of $120^{\circ}$ or less, the influence range of the curved part is determined to be at the $1.0 \mathrm{D}$ point, and with a CCV of 120 or above, the entire section is determined to be a straight part.

2. Analysis of the planar region showed that in the case of a concave-shaped wall, the horizontal displacement at all angles increases with an increase in separation distance from the center of the curved part $(0.0 \mathrm{D})$ and converges to the straight part displacement from the $1.0 \mathrm{D}$ point. Therefore, the influence range of concave RSWs is estimated to be $1.0 \mathrm{D}$. We can see that the horizontal displacement decreased from the straight part to the curved part. The cause of this finding is likely due to the arching effect of the backfill.

3. Based on the analysis results, the reinforcement area is determined to be $0.3 \mathrm{H}-0.7 \mathrm{H}$ at all angles in the case of the convex wall, and the maximum horizontal displacement occurred at $0.5 \mathrm{H}$, which is similar to the results of a previous study [12]. It is thought that more reinforcement is required at an angle of approximately $120^{\circ}$ in particular, which is considered to be a straight part.

4. Based on the analysis results, for the concave wall, the displacement in the curved part is smaller than that in the straight part. Based on the displacement analysis, there seems to be no effect from angles for the areas greater than $1.0 \mathrm{D}$, but there are some differences related to angles in the areas below 1.0 D which are considered to be due to the combined reinforcement effect of the reinforcement installation and the arching effect.

5. Based on the overall results of this study, the influence range of curved parts for all shapes and angles is $1.0 \mathrm{D}$. When comparing the results of convex and concave shapes, the effect of curved parts occurs at angles of $120^{\circ}$ or less, and, in the case of angles above $120^{\circ}$, the difference in displacement between the straight and curved parts is small enough that there is no boundary between the curved and straight parts above $120^{\circ}$. Existing design criteria for RSWs specify the reinforcement area from the center of the curved part to $0.5 \mathrm{D}$ for the curved part. The curved 
part influence range in this study was $1.0 \mathrm{D}$. Therefore, it is recommended that the reinforcement area is increased from $0.5 \mathrm{D}$ to $1.0 \mathrm{D}$.

6. In this study, the relative differences in displacement between the curved and straight parts of RSWs were analyzed, and the influence range and reinforcement area of the curved part were presented. However, the effects of the curved parts may vary depending on various conditions such as the strain and height of RSWs, the radius of curvature, the type of reinforcements, and the spacing of the installation. The number of cases investigated in this study is insufficient and limits the ability to use the findings to generalize the curved part influence range for RSWs. Therefore, further indoor experiments are needed with more cases, and numerical studies and in-situ tests are also required to verify the results of this study.

Author Contributions: Conceptualization, Y.J.K. and H.S.J.; methodology, H.S.J. and Y.J.L.; software, D.W.O., H.H.Y.; formal analysis, Y.J.K., D.W.O., and H.S.J.; investigation, D.W.O. and Y.J.L.; writing-original draft, Y.J.K., M.S., H.H.Y.; writing-review \& editing, H.S.J. and Y.J.L. and M.S.; supervision, H.S.J. and Y.J.L. All authors have read and agreed to the published version of the manuscript.

Funding: This research was supported by the National Research Foundation of Korea (NRF) Grant funded by the Korea government (MSIP). (No. NRF-2017R1A2B2012993).

Conflicts of Interest: The authors declare no conflicts of interest.

\section{References}

1. Lee, G.W.; Jo, S.D.; Han, J.G.; Hong, K.W. Evaluation on Stability of Reinforced Earth Wall using Geosynthetic Strip with Rounded Band Anchor. J. Korean Geosynth. Soc. 2012, 11, 43-51. [CrossRef]

2. Kim, H.T.; Bang, Y.K.; Park, J.Y.; Choi, D.H.; Lee, H.K.; Youn, K.W. Quasi-Three Dimensional Stability Analysis of the Geosynthetic-Reinforced Soil Retaining Wall. Korean Geosynth. Soc. 1998, 14, 177-201.

3. Yoo, C.S.; Jung, H.Y.; Jung, H.S. A case study in a rainfall induced failure of geosynthetics-reinforced segmental retaining wall. Korean Geosynth. Soc. 2005, 4, 17-25.

4. Jung, H.S. Comparison of Behaviour of Straight and Curved Mechanically Stabilized Earth Walls from Numerical Analysis Results. Korean Geosynth. Soc. 2017, 16, 83-92.

5. Lee, S.Y.; Jung, H.S.; Kim, Y.J.; Lee, Y.J.; Oh, D.W. A Study on Behavior Characteristics of Reinforcement Zone of Block Type Mechanically Stabilized Earth Wall by Field Measurement in Curved Section. Korean Geosynth. Soc. 2019, 18, 23-36.

6. Korean Geosynthetics Society. Pracrice of Reinforced Soil Method; CIR: Milan, Italy, 2010; pp. 1-141, 187-240.

7. Korea Construction Standards Center. KDS 1180102018 Reinforced Soil Retaining Wall. 2018. Available online: http://kcsc.re.kr/StandardCode/Viewer/33 (accessed on 1 July 2019).

8. Berg, R.R.; Christopher, B.R.; Samtani, N.C. Design and Construction of Mechanically Stabilized Earth Walls and Reinforced Soil Slopes (Volume I); FHWA-NHI-10-024; National Highway Institute Federal Highway Administration, Department of Transportation: Washington, DC, USA, 2009.

9. AASHTO. LRFD Bridge Design Specifications, 6th ed.; American Association of State Highway and Transportation Officials: Washington, DC, USA, 2012.

10. NCMA. Segmental Retaining Walls Best Practices Guide for the Specification, Design, Construction and Inspection of SRW Systems; National Concrete Masonry Association: Herndon, VA, USA, 2016.

11. Wong, K.S.; Broms, B.B.; Chandrasekaran, B. Failure Modes and Model Test of a Geotextile Reinforced Wall. Geotextile Geomembr. 1994, 13, 475-493. [CrossRef]

12. Ki, J.S.; Rew, W.H.; Kim, S.K.; Chun, B.S. A Behavior of Curve Section of Reinforced Retaining Wall by Model Test. Korean Soc. Civ. Eng. 2012, 32, 249-257. [CrossRef]

13. Lee, G.W.; Jo, S.D. Deformation of Model Reinforced Soil Walls with Different Surcharge Loads. J. Korean Geosynth. Society 2008, 7, 41-47.

14. Lee, J.H.; Oh, D.W.; Kong, S.M.; Jung, H.S.; Lee, Y.J. Investigation of Behaviours of Wall and Adjacent Ground Considering Shape of Geosynthetic Retaining Wall. Korean Geosynth. Soc. 2018, 17, 95-109.

15. Yoo, C.S.; Kim, S.B.; Kim, Y.H.; Song, A.R. Full-scale loading test of geosynthetic reinforced segmental retaining wall. In Proceedings of the Fall 2006 Geosynthetics Conference, Suwon, Korea, 1 December 2006. 
16. Jung, H.S. Behavior of a Full-Scale Geosynthetic-Reinforced Segmental Retaining Wall in a Tiered ConFigureuration. Master's Thesis, SungKyunKwan University, Seoul, Korea, 2004.

17. PhotoModeler Scanner. Quantifying the Accuracy of Dense Surface Modeling within PhotoModeler Scanner. 2012. Available online: https://www.photomodeler.com/article/quantifying-the-accuracy/ (accessed on 1 July 2019).

18. Smith, M.J.; Kokkas, N. Assessing the Photogrammetric Potential of Cameras in Portable Devices. In Proceedings of the International Archives of the Photogrammetry, Remote Sensing and Spatial Information Sciences, Volume XXXIX-B5, 2012 XXII ISPRS Congress, Melbourne, Australia, 25 August-1 September 2012.

19. Janssen, H.A. Versuche uber Getreidedruck in Silozellen. Pratial Engl. Transl. Proceeding Inst. Civil Eng. Lond. Engl. 1895, 39, 1045-1049.

(C) 2020 by the authors. Licensee MDPI, Basel, Switzerland. This article is an open access article distributed under the terms and conditions of the Creative Commons Attribution (CC BY) license (http://creativecommons.org/licenses/by/4.0/). 